\title{
Profile of Malignancies among Elderly Patients: A Study in the National Institute of Cancer Research \& Hospital (NICRH), Dhaka, Bangladesh
}

\author{
Md. Mostafa Kamal ${ }^{1 *}$, Md. Johirul Islam², Md. Habibullah Talukder ${ }^{3}$, Nausheen Laila ${ }^{4}$, Md. Nafis Fuad ${ }^{5}$
}

${ }^{1}$ Associate Professor, Cancer Epidemiology, National Institute of Cancer Research \& Hospital (NICRH), Dhaka, Bangladesh

${ }^{2}$ Associate Professor, Cancer Epidemiology, NICRH, Dhaka, Bangladesh

${ }^{3}$ Associate Professor \& Head, Cancer Epidemiology, NICRH, Dhaka, Bangladesh

${ }^{4}$ Research Assistant, Cancer Epidemiology, NICRH, Dhaka, Bangladesh

${ }^{5} \mathrm{HMO}$, NICRH, Dhaka, Bangladesh

DOI: $10.36347 /$ sjams.2020.v08i09.008

| Received: 31.08.2020 | Accepted: 08.09.2020 | Published: 09.09.2020

*Corresponding author: Dr. Md. Mostafa Kamal

Abstract

Original Research Article

Background: Global burden of cancer is increasing day by day. As a consequence of growing, and ageing population, an important part of this increase is predicted to concern developing countries like Bangladesh. We have very limited data regarding this issue. Aim of the study: The aim of this study was to find out the profile of geriatric cancers in National Institute of Cancer Research and Hospital, (NICRH), Dhaka, Bangladesh during 2012 to 2014. Methodology: It was a retrospective study using hospital based cancer registry records from January 2012 to December 2014 . All geriatric patients with cancer, aged $\geq 65$ years diagnosed by means of histological or cytological examination during that period, were included in the study. Results: Out of total 5294 patients, $78.30 \%(\mathrm{n}=4145)$ were male and $21.70 \%$ $(\mathrm{n}=1149)$ were female. We found the highest number of patients from 65-74 years' age group which was $73.88 \%$. Then $21.10 \%, 4.14 \%$ and $0.89 \%$ were from $75-84,85-94$ and $\geq 95$ years' age groups respectively. About $44.94 \%$ $(n=2379)$ of the patients were from Dhaka division and around $29.74 \%$ patients $(n=1045)$ were from Chattogram division. Least number of patients came from Rangpur $(2.13 \%, \mathrm{n}=113)$ and Sylhet $(2.72 \%, \mathrm{n}=144)$ divisions. In total $38.21 \%(\mathrm{n}=1584)$ male $2.35 \%(\mathrm{n}=27)$ female patients were current smokers. In male patients lung (In male: $36.36 \% \&$ in female: $25.76 \%$ ) was the leading site of cancer in each year followed by oesophageal cancer (In male: $7.12 \%$ \& in female: $(11.31 \%)$. But separately there was found a noticeable association of breast in female patients and it was $13.49 \%$ in female group. Conclusion: In male the pattern is almost identical with that of the adult cancers. In female notable deviation was noted from usual adult female cancer as most of the years lung cancer led the tally.

Keywords: Cancer registry, Geriatric malignancies, Cancer profile.

Copyright @ 2020: This is an open-access article distributed under the terms of the Creative Commons Attribution license which permits unrestricted use, distribution, and reproduction in any medium for non-commercial use (NonCommercial, or CC-BY-NC) provided the original author and source are credited.

\section{INTRODUCTION}

Global burden of cancer is increasing day by day. As a consequence of growing, and ageing population, an important part of this increase is predicted to concern developing countries like Bangladesh. We have very limited data regarding this issue. The aim of this study was to find out the profile of geriatric cancers in National Institute of Cancer Research and Hospital, (NICRH), Dhaka during 2012 to 2014. Ageing is a universal process observed in every living creature. Actually it begins from intrauterine life, and continues up to death. Ageing induces many changes in physiological functions of organs, and systems. Nowadays, with the advent of new technologies, disease, and mortality rates have decreased, birth rates have dropped and as a result prolongation of life span occurred. The World Health Organization (WHO) defines old age as the period of life starting from 65 years of age [1]. According to WHO, in the year 2025 people aged 65 years and over will be expected to reach 800 million [2]. Ageing is defined as irreversible structural and functional changes in molecules, tissues, organs, and systems of the body which become apparent with advanced age. One of the predominant causes of mortality and morbidity is cancer whose incidence increases with age. Although cancer affects each age group nearly $60 \%$ of the cancer cases and $70 \%$ of the cancer related mortalities occur in individuals aged 65 or older [3]. Global burden of cancer is increasing day by day. As a consequence of growing, and ageing population, an important part of this increase is predicted to concern developing countries like Bangladesh. Because of limitations in the application of screening programs, early diagnosis, and access to treatment, further increases in the incidence of 
cancer, and cancer-related mortality rates have been anticipated $[4,5]$.

\section{Materials ANd Methods}

This study was conducted in the National Institute of Cancer Research and Hospital, (NICRH), Dhaka, Bangladesh. We used three (3) years hospital records in this retrospective study from January 2012 to December 2014. The intervention was approved by the ethical committee of the mentioned institution. Proper written consents were taken from all the participants before starting the main part of this intervention. A predesigned questioner was used for collecting necessary date of the participants. All geriatric patients with cancer, aged $\geq 65$ years diagnosed by means of histological or cytological examination during that period, were included in the study. Although at through the first screening we got more than 26 thousand patients but according to their age and inclusion criteria of this study we finalized 5294 patients as the study population. The profile of geriatric cancer was studied focusing on the prevalence of tumors according to age, sex, residence and topography. Data were processed by editing and post-coding and analyzed by SPSS for Windows (IBM SPSS Statistics for Windows, version 25.0, Armonk, NY: IBM Corp.) software.

\section{RESULTS}

There were 26385 confirmed new cases attended outpatient department of NICRH during
January 2012 to December 2014. Among which 5294 belong to geriatric group (65 years or older). An average of 1765 cases attended per year. The geriatric tumours comprised of $20 \%$ of all malignancies during theses 3 years time. Out of total 5294 patients, $78.30 \%$ $(n=4145)$ were male and $21.70 \%(n=1149)$ were female with a male to female ratio of 3.6:1. Almost all were (94\%) Muslim. Distribution of the geriatric patients by age group had been disseminated. In analyzing the ages of the participants we found the highest number of patients from 65-74 years' age group which was $73.88 \%$. Then $21.10 \%, 4.14 \%$ and $0.89 \%$ were from 75 $84,85-94$ and $\geq 95$ years' age groups respectively. About $44.94 \% \quad(n=2379)$ of the patients were from Dhaka division and around $29.74 \%$ patients $(n=1045)$ were from Chattogram division. Least number of patients came from Rangpur $(2.13 \%, \mathrm{n}=113)$ and Sylhet $(2.72 \%, \mathrm{n}=144)$ divisions. More than $38.21 \%(\mathrm{n}=1584)$ male patients were current smokers whereas only $2.35 \%$ $(n=27)$ female patients were current smokers. In male patients lung (In male: $36.36 \% \&$ in female: $25.76 \%$ ) was the leading site of cancer in each year followed by oesophageal cancer (In male: $7.12 \%$ \& in female: $(11.31 \%)$. But separately there was found a noticeable association of breast in female patients and it was $13.49 \%$ in female group. Stomach cancer occupied the third place in each year. Among female patients lung was the leading cancer in three successive years starting form 2012. So the other notable cancers in women were breast cancer, oesophageal cancer and lymphoma. Year wise five leading cancers are shown in table.

Table-1: Yearly distribution of the geriatric patients by age group $(n=5294)$

\begin{tabular}{|c|c|c|c|c|c|c|}
\hline \multirow[t]{3}{*}{ Age in Year } & \multicolumn{4}{|l|}{ Sex } & \multirow{2}{*}{\multicolumn{2}{|c|}{ Total }} \\
\hline & \multicolumn{2}{|l|}{ Male } & \multicolumn{2}{|c|}{ Female } & & \\
\hline & $\mathrm{n}$ & $\%$ & $\mathrm{n}$ & $\%$ & $\mathrm{n}$ & $\%$ \\
\hline \multicolumn{7}{|l|}{ Year 2012} \\
\hline $65-74$ & 818 & 72.20 & 224 & 77.51 & 1042 & 73.28 \\
\hline $75-84$ & 243 & 21.45 & 54 & 18.69 & 297 & 20.89 \\
\hline $85-94$ & 59 & 5.21 & 8 & 2.77 & 67 & 4.71 \\
\hline$\geq 95$ & 13 & 1.15 & 3 & 1.04 & 16 & 1.13 \\
\hline Total & 1133 & $100 \%$ & 289 & $100 \%$ & 1422 & $100 \%$ \\
\hline \multicolumn{7}{|l|}{ Year 2013} \\
\hline $65-74$ & 950 & 72.91 & 221 & 79.50 & 1171 & 74.07 \\
\hline $75-84$ & 293 & 22.49 & 48 & 17.27 & 341 & 21.57 \\
\hline $85-94$ & 52 & 3.99 & 8 & 2.88 & 60 & 3.80 \\
\hline$\geq 95$ & 8 & 0.61 & 1 & 0.36 & 9 & 0.57 \\
\hline Total & 1303 & $100 \%$ & 278 & $100 \%$ & 1581 & $100 \%$ \\
\hline \multicolumn{7}{|l|}{ Year 2014} \\
\hline $65-74$ & 1251 & 73.20 & 447 & 76.80 & 1698 & 74.12 \\
\hline $75-84$ & 370 & 21.65 & 109 & 18.73 & 479 & 20.91 \\
\hline $85-94$ & 69 & 4.04 & 23 & 3.95 & 92 & 4.02 \\
\hline$\geq 95$ & 19 & 1.11 & 3 & 0.52 & 22 & 0.96 \\
\hline Total & 1709 & $100 \%$ & 582 & $100 \%$ & 2291 & $100 \%$ \\
\hline
\end{tabular}


Table-2: Distribution of the geriatric patients by age group $(n=5294)$

\begin{tabular}{|c|c|c|c|c|c|c|}
\hline \multirow[t]{3}{*}{ Age (Year) } & \multicolumn{4}{|l|}{ Sex } & \multirow{2}{*}{\multicolumn{2}{|c|}{ Total }} \\
\hline & \multicolumn{2}{|l|}{ Male } & \multicolumn{2}{|c|}{ Female } & & \\
\hline & $\mathrm{n}$ & $\%$ & $\mathrm{n}$ & $\%$ & $\mathrm{n}$ & $\%$ \\
\hline \multicolumn{7}{|c|}{ Total three years period } \\
\hline 65-74 & 3019 & 72.83 & 892 & 77.63 & 3911 & 73.88 \\
\hline $75-84$ & 906 & 21.86 & 211 & 18.36 & 1117 & 21.10 \\
\hline $85-94$ & 180 & 4.34 & 39 & 3.39 & 219 & 4.14 \\
\hline$\geq 95$ & 40 & 0.97 & 7 & 0.61 & 47 & 0.89 \\
\hline Total & 4145 & $100 \%$ & 1149 & $100 \%$ & 5294 & $100 \%$ \\
\hline
\end{tabular}

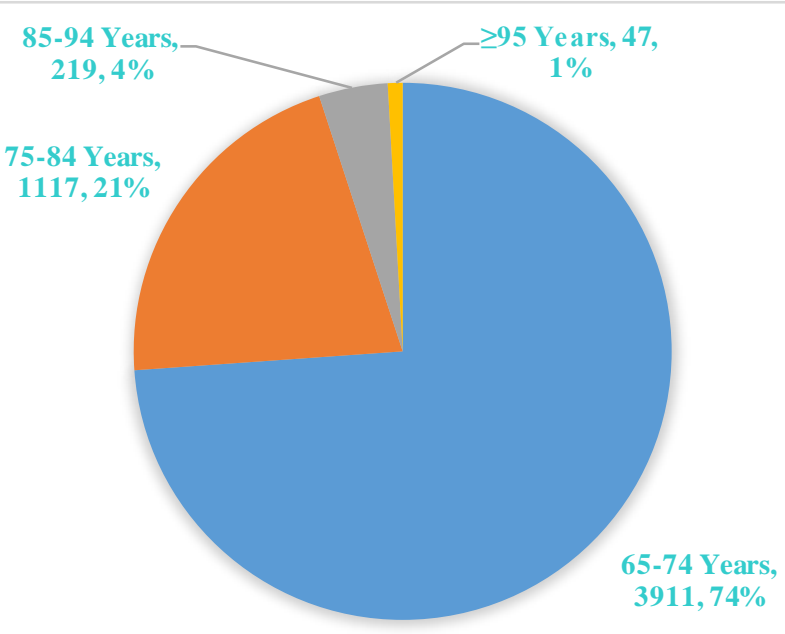

Fig-1: Age distribution of total participants $(n=5294)$

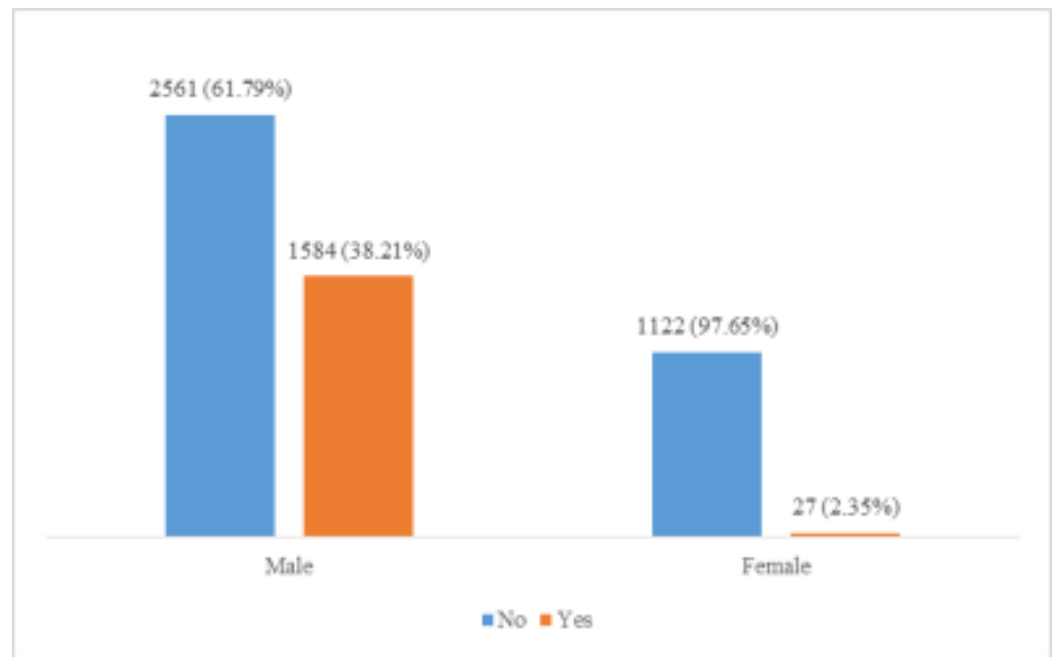

Fig-2: Distribution of smoking habit total participants $(\mathbf{n}=5294)$ 
Table-3: Yearly distribution of participants regarding organ associated with malignancies (5294)

\begin{tabular}{|l|l|l|l|l|l|}
\hline \multirow{2}{*}{ Organ } & \multicolumn{2}{|l|}{ Male (n=1133) } & \multirow{2}{*}{ Organ } & \multicolumn{2}{l|}{ Female (n=289) } \\
\cline { 2 - 4 } & $\mathrm{n}$ & $\%$ & & $\mathrm{n}$ & $\%$ \\
\hline Year 2012 (Male: 1133 \& Female: 289) \\
\hline Lung & 355 & 31.33 & Lung & 48 & 16.61 \\
\hline Oesophagus & 88 & 7.77 & Breast & 32 & 11.07 \\
\hline Stomach & 59 & 5.21 & Oesophagus & 30 & 10.38 \\
\hline Liver & 41 & 3.62 & Cervix & 28 & 9.69 \\
\hline Prostate & 40 & 3.53 & Lymphoma & 16 & 5.54 \\
\hline Year 2013 (Male: 1303 \& Female: 278) \\
\hline Lung & 496 & 38.07 & Lung & 52 & 18.71 \\
\hline Oesophagus & 93 & 7.14 & Breast & 43 & 15.47 \\
\hline Stomach & 65 & 4.99 & Oesophagus & 43 & 15.47 \\
\hline Liver & 56 & 4.30 & Cervix & 28 & 10.07 \\
\hline Prostate & 43 & 3.30 & Lymphoma & 15 & 5.40 \\
\hline Year 2014 (Male: 1709 \& Female: 582) \\
\hline Lung & 656 & 38.39 & Lung & 96 & 16.49 \\
\hline Oesophagus & 114 & 6.67 & Breast & 80 & 13.75 \\
\hline Stomach & 79 & 4.62 & Oesophagus & 57 & 9.79 \\
\hline Liver & 66 & 3.86 & Cervix & 39 & 6.70 \\
\hline Prostate & 53 & 3.10 & Lymphoma & 29 & 4.98 \\
\hline
\end{tabular}

Table-4: Distribution of total participants regarding organ associated with malignancies (5294)

\begin{tabular}{|l|l|l|l|l|l|}
\hline \multirow{2}{*}{ Organ } & \multicolumn{2}{|l|}{ Male $(\mathbf{n}=\mathbf{4 1 4 5})$} & \multirow{2}{*}{ Organ } & \multicolumn{2}{l|}{ Female (n=1149) } \\
\cline { 2 - 3 } \cline { 5 - 6 } & $\mathrm{n}$ & $\%$ & & $\mathrm{n}$ & $\%$ \\
\hline Year 2012-2014- & \multicolumn{5}{|l}{} \\
\hline Lung & 1507 & 36.36 & Lung & 296 & 25.76 \\
\hline Oesophagus & 295 & 7.12 & Breast & 155 & 13.49 \\
\hline Stomach & 203 & 4.90 & Oesophagus & 130 & 11.31 \\
\hline Liver & 163 & 3.93 & Cervix & 95 & 8.27 \\
\hline Prostate & 136 & 3.28 & Lymphoma & 60 & 5.22 \\
\hline
\end{tabular}

\section{DiscUSSION}

Like rest of the world, cancer is a public health problem with increasing importance in our country too. Prolongation of overall lifetime leads to increase in the older population in our country. As per World Bank report the life expectancy at birth in Bangladesh was 71.23 years in 2014 [6]. The exact number or percentage of geriatric patients suffering from cancer is not known. In hospital cancer registry 2014 report of NICRH the proportional incidence among this group was reported as $20.6 \%$. In the current study we found this rate near about $20 \%$. This percentage is more or less comparable with other countries rate. In Turkey, $27 \%$ of the patients diagnosed as cancer are aged 65 years and over [3]. In the United States of America more than $60 \%$ of the cancer cases are seen in old individuals aged 65, and over [7]. In the current study the male to female ratio was $3.6: 1$. The exact cause of such male preponderance is not clear. Personal habits, social norms and history of occupational hazards could be the three important underlying factors. Further study in this regard is warranted. In the current study about $45 \%$ of the patients were from Dhaka division. It does not necessarily mean that people of Dhaka division suffers more from cancer. Physical location of the institute might be playing role for this type of observation. Only well designed population based cancer registry can resolve such dilemma. In our study lung was the leading site of cancer in each year among males. Lung cancer has the shortest survival times among other cancer types, and takes the lead among cancer- related deaths in the whole world [8]. Half of the cases with lung cancer are diagnosed in the advanced stage [8]. In the USA, median age of newly diagnosed cases with NSCLC is 68 years, while $40 \%$, and $14 \%$ of these cases are over 70 , and 80 years of age, respectively [9]. According to American Cancer Society (ACS) lung cancer is responsible from nearly $27 \%$ of all cancer-related deaths [7]. Owing to the decrease in the rate of smoking in Europe, and USA, decrease in incidence of lung cancer has been observed more frequently in men. Lung cancer -specific mortality rates between genders reflect smoking status, rates of quitting smoking, and historical differences within the last 50 years [8]. According to Globocan 2018 data published by International Cancer Agency, lung cancer ranks $2^{\text {nd }}$ top position in men in Bangladesh. Similar trend was found in the European Union Countries, and in the USA [8]. In smokers the risk is higher relative to nonsmokers [8]. In adult female breast cancer was the leading cancer [10]. Prolonged exposure to carcinogenic agents such as secondary smoking, DNA damage accumulation, tumor suppressor gene defects, impairment of cellular repair 
mechanisms, oncogenic activation, and attenuation of immunity have been held responsible for higher incidence of cancer in older individuals [3]. Since carcinogenesis is a very long process, emergence of cancer in advanced ages is a natural event. In other two years cervical cancer out placed lung cancer. Both incidence, and mortality rates of invasive cervical cancer increases with age. Cervical cancer is a very costly disease which has a serious impact on health system, and population. In patients aged 65, and over cervical cancer has mortality rates ranging between 40 , and $50 \%$. However regular screening decreases cervical cancer risk at a rate of 80 percent [8]. Every year nearly 500.000 women are diagnosed as cervical cancer, and approximately $80 \%$ of them are seen in developing countries [11]. Geriatric patients are not 'big' adult patients. Treatment, and care for older patients with cancer should be individualized rather than focusing on age of the patient. With comprehensive geriatric evaluation, risks, and benefits of the available treatment alternatives should be properly determined. Early diagnosis, treatment, and screening programs will be the key in decreasing incidence rates of cancer in elderly.

\section{Limitations of the study}

This was a single center study with limited sample size. So, the study results may not be reflected to the scenarios of the whole country.

\section{CONCLUSION \& RECOMMENDATION}

In male the pattern is almost identical with that of the adult cancers. In female notable deviation was noted from usual adult female cancer as most of the years lung cancer led the tally. The findings of this study may be helpful in the treatment arena and in further similar studies. But this was a single centered study. So the findings of this study may not reflect the exact scenario of the whole country.

\section{REFERENCES}

1. WHO. Glossary of terms used in the "Health for All" Series N. 1-8. Geneva: World Health Organization, 1984.

2. Information needs for research, policy and action on ageing and older adults: Report of a workshop on creating a Minimum Data Set (MDS) for research, policy and action on ageing and the aged in Africa. Geneva: World Health Organization, 2000 (document WHO/NMH/HPS/00.7).

3. Alan O, Gursel O, Unsal M, Altın S, Kılcıksız S. Oncologic Approach in Geriatric Patients. Okmeydanı Tıp Dergisi. 2013; 29:94-8.

4. Stewart BW, Wild CP, editors. World Cancer Report 2014. Lyon: International Agency for Research on Cancer, 2014

5. De Martel C, Ferlay J, Franceschi S, Vignat J, Bray F, Forman D, Plummer M. Global burden of cancers attributable to infections in 2008: a review and synthetic analysis. The lancet oncology. 2012 Jun 1;13(6):607-15.

6. Life expectancy at birth - Bangladesh (Internet). Washington (DC): The World Bank; (cited 2020 July 10). Available from https://data.worldbank.org/indicator/

7. American Society of Clinical Oncology (Internet). 2012 (cited 2020 July 7). Available from: www.asco.org.

8. Siegel R, Ma J, Zou Z and Jemal A. Cancer statistics, 2014. CA: A Cancer Journal for Clinicians. 2014; 64(1): 9-29.

9. Koksal D. Management of Non-Small Cell Lung Cancer in the Elderly. Solunum. 2013; 15:14-20.

10. National Institute of Cancer Research \& Hospital. Cancer Registry Report 2014 (Internet). 2015 (cited 2020 July 9). Available at: http://nicrh.gov.bd/reports/Hospital Cancer Registry 2014/

11. Şahbaz A, Erol O. HPV vaccine practice. Obstet Gynecol. 2014; 2:126-30. 